\title{
Hormone Replacement Therapy - Computer Assisted Individualized Approach
}

\author{
BM Petrikovsky* \\ Nassau University Medical Center USA
}

*Corresponding author: BM Petrikovsky, Professor and former chair of Obstetrics and Gynecology, Nassau University Medical Center, USA.

Received Date: December 13, 2018

Published Date: December 20, 2018

\section{Introduction}

The onset of menopause occurs at around the age of 50.1 Some health issues, including but not limited to cardiovascular disease, metabolic syndromes, osteoporosis, cancer, and cognitive decline, are more prevalent in women in the years that follow. The onset of menopause is an ideal time to institute preventative strategies that increase the quality and length of women's lives [1].

The use of hormone-replacement therapy (HRT) has undergone many changes since it was first introduced into clinical practice in the 1940s. At present, the pendulum seems to be swinging back to more acceptance of its use, following a marked reduction in prescriptions after the results of the Women's Health Initiative (WHI) study were published in the early 2000s [2]. HRT was shown to significantly decrease the incidence of menopausal symptoms, risk of osteoporotic fractures, and improve the overall quality of life. In younger, healthy women (aged 50-60 years), the risk-benefit balance is clearly in favor of using HRT [1-3]. HRT is not risk-free. An increased risk of stroke with HRT has been reported in several studies $[4,5]$.

The majority of studies on breast cancer and HRT have shown an increased risk with estrogen use, depending on its dose and duration of treatment [6]. Estrogen, in the absence of progestogen, may also lead to hyperplasia of the endometrium and ultimately, to well differentiated uterine cancer [7].

The use of progestogen in combination with estrogen, reduces the risk of cancer of the uterus [1,7]. Compounded "bioidentical" hormones (so called "natural estrogens") are used widely in the USA. Their popularity has been driven by unsubstantial claims of increased safety and efficacy. In reality, these unregulated formulations might be less safe and efficacious than FDA approved HRT products [8].

In an extensive review on the topic, Lobo RA, et al. [3] writes: "While for symptom control, we can titrate up to an effective dose, we do not know what dose of estrogen is sufficient to prevent coronary disease or osteoporosis in a given woman [9].

There is substantial evidence that a low-dose of medication is as effective in preventing bone loss and treatment of menopausal symptoms with less bleeding and other side effects than higher dose [10-14].

\section{Route of HT Administration}

The route of administration of HT is particularly important. Women with cardiovascular risk factors or those starting therapy after more than 10 years after the onset of menopause may be candidates for low-dose transdermal estrogen [1]. The use of transdermal estrogen also has the additional safety in that it avoids the hepatic "first pass" effect. Studies show no increased risk of blood clots, even in high-risk women, when transdermal estrogens are used $[12,13]$. Shoupe, 1 in her extensive review of the topic, identified the following important aspects of HRT:

\section{Minimizing the dose}

Selecting the lowest effective dose for menopausal symptoms lowers the risk of side effects. As women age, their metabolic rate declines and gradual dose reduction should be considered.

\section{Delivery method}

Use of non-oral estrogen delivery systems - such as patches, minimizes the effects of estrogen on the liver.

\section{Consider adding a progestin}

Adding a progestin to estrogen therapy is recommended to protect the endometrium.

In summary, personalized approaches should be available to enable prescribing based on a woman's genotype [9]. Targeted therapies should make for more effective and safer types and doses of HRT. 
We propose a computer software program to provide individual therapy to postmenopausal women based on the following parameters: Age, weight, uterine status (present, absent), individual hormonal levels (estradiol, testosterone). Those parameters were chosen because they appear to be most important in treatment outcomes [1-4]. The computer program was designed to develop the minimal effective dose of HRT to control patients' symptoms (Table 1).

Table 1: Some of the proposed components of HRT.

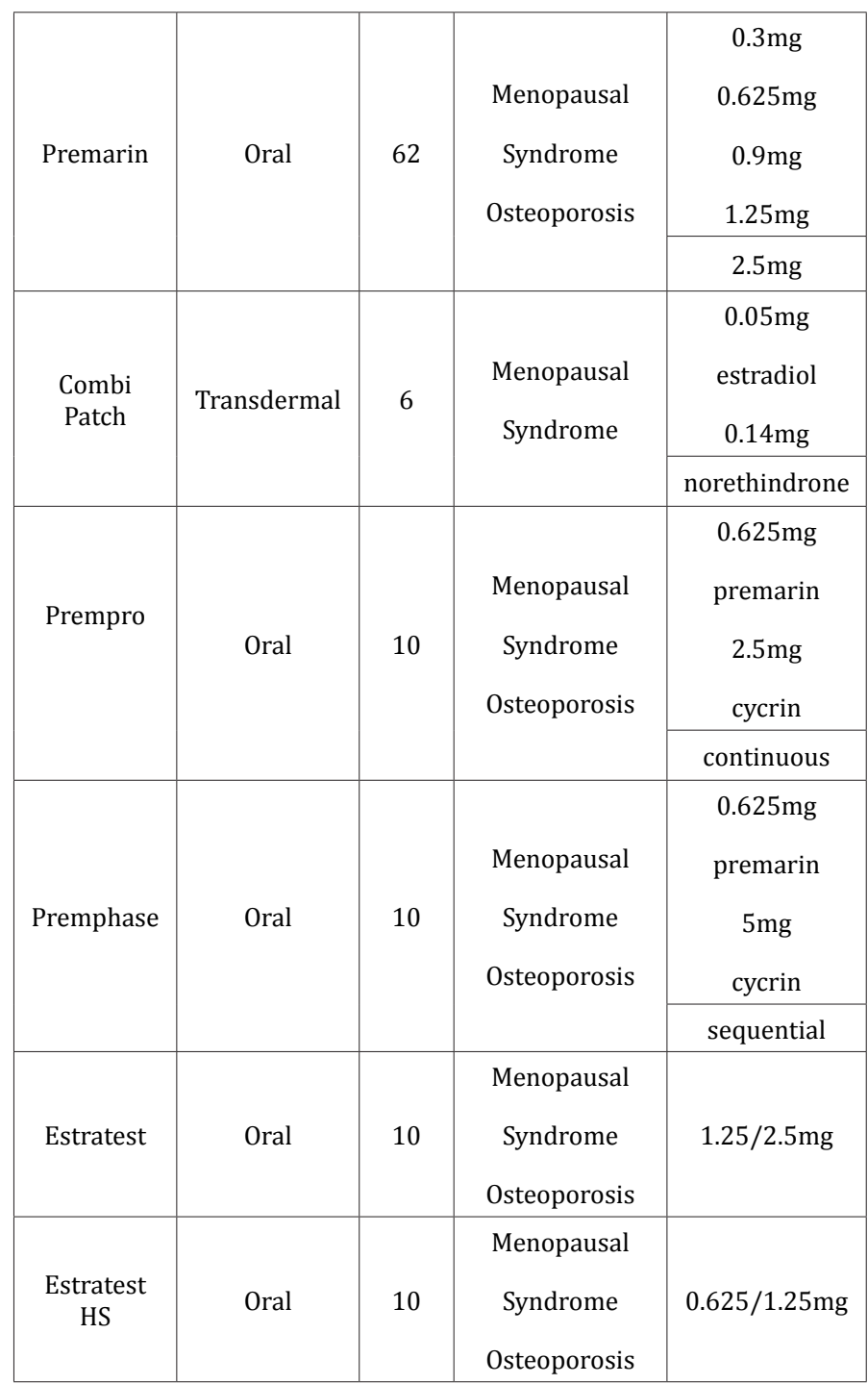

The program calculates a minimal needed portion of ERT transdermal patch (in most cases Minivelle) to accommodate the treatment needs of an individual patient after all of her data had been entered into the computer.

The computer calculates what minimal portion of the ERT transdermal patch will alleviate the patient's symptoms. The preliminary results showed that the customized approach allowed us to achieve our therapeutic goals by utilizing less of the medicine in $65 \%$ of women.1,4 Definitive studies are currently in progress.

\section{Acknowledgement}

None.

\section{Conflict of interest}

No conflict of interest.

\section{References}

1. Shoupe D (2012) Individualizing hormone therapy. Minerva Med 103(5): 343-352.

2. Rossouw JE, Anderson GL, Prentice RL, LaCroix AZ, Kooperberg C, et al. (2002) Risks and benefits of estrogen plus progestin in healthy postmenopausal women: principal results From the Women's Health Initiative randomized controlled trial. JAMA: 288(3): 321-333.

3. Lobo RA, Davis SR, De Villiers TJ, Gompel A, Henderson VW, et al. (2014) Prevention of diseases after menopause. Climacteric 17: 540-556.

4. Henderson VW, Lobo RA (2012) Hormone therapy and the risk of stroke: perspectives 10 years after the Women's Health Initiative trials. Climacteric 15: 229-234.

5. Grodstein F, Manson JE, Stampfer MJ, Rexrode K (2008) Postmenopausal hormone therapy and stroke: role of time since menopause and age at initiation of hormone therapy. Arch Intern Med 168: 861-866.

6. (1997) Breast cancer and hormone replacement therapy: collaborative reanalysis of data from 51 epidemiological studies of 52,705 women with breast cancer and 108,411 women without breast cancer. Collaborative Group on Hormonal Factors in Breast Cancer. Lancet 350 (9084): 10471059.

7. Ziel HK, Finkle WD (1975) Increased risk of endometrial carcinoma among users of conjugated estrogens. N Engl J Med 293: 1167-1170.

8. Santoro N, Braunstein GD, Butts CL, Martin KA, McDermott M, et al. (2016) Compounded bioidentical hormones in endocrinology practice: An Endocrine Society Scientific Statement. J Clin Endocrinol Metab 101(4): 1318-1343.

9. Lobo RA (2017) Hormonal-replacement therapy: current thinking Endocrinol 13(4): 220-231.

10. van der Stege JG, Groen H, van Zadelhoff SJ, Lambalk CB, Braat DD, et al. (2008) Decreased androgen concentrations and diminished general and sexual well-being in women with premature ovarian failure. Menopause 15(1): 23-31.

11. Buster JE, Kingsberg SA, Aguirre O, Brown C, Breaux JG, et al. (2005) Testosterone patch for low sexual desire in surgically menopausal women: a randomized trial. Obstet Gynecol 105(5 pt I): 944-952.

12. Simon J, Braunstein G, Nachtigall L, Utian W, Katz M, et al. (2005) Testosterone patch increases sexual activity and desire in surgically menopausal women with hypoactive sexual desire disorder. J Clin Endocrinol Metab 90(9): 5226-5233.

13. Braunstein GD, Sundwall DA, Katz M, Shifren JL, Buster JE, et al. (2005) Safety and efficacy of a testosterone patch for the treatment of hypoactive sexual desire disorder in surgically menopausal women: a randomized, placebo-controlled trial. Arch Intern Med 165(14): 1582-1589.

14. Zharov EV, Petrikovsky BM. Personal communication. 